\title{
Novel system uses probasin-based promoter, transcriptional silencers and amplification loop to induce high-level prostate expression
}

\author{
Jan Woraratanadharm ${ }^{1}$, Semyon Rubinchik ${ }^{1}$, Hong $\mathrm{Yu}^{1}$ and John Y Dong*1,2
}

Address: ${ }^{1}$ Department of Microbiology and Immunology, Medical University of South Carolina, Charleston, South Carolina, USA and ${ }^{2}$ Division of Cancer Therapeutics, GenPhar Inc., Mount Pleasant, South Carolina, USA

Email: Jan Woraratanadharm - jworara@genphar.com; Semyon Rubinchik - rubinchr@musc.edu; Hong Yu - yuho@musc.edu; John Y Dong* - dongj@musc.edu

* Corresponding author

Published: 12 February 2007

BMC Biotechnology 2007, 7:9 doi:10.1 186/1472-6750-7-9
Received: 28 September 2006

Accepted: I 2 February 2007

This article is available from: http://www.biomedcentral.com/1472-6750/7/9

(C) 2007 Woraratanadharm et al; licensee BioMed Central Ltd.

This is an Open Access article distributed under the terms of the Creative Commons Attribution License (http://creativecommons.org/licenses/by/2.0), which permits unrestricted use, distribution, and reproduction in any medium, provided the original work is properly cited.

\begin{abstract}
Background: Despite several effective treatment options available for prostate cancer, it remains the second leading cause of cancer death in American men. Thus, there is a great need for new treatments to improve outcomes. One such strategy is to eliminate cancer through the expression of cytotoxic genes specifically in prostate cells by gene therapy vectored delivery. To prevent systemic toxicity, tissue- and/or cancer-specific gene expression is required. However, the use of tissue- or cancer-specific promoters to target transgene expression has been hampered by their weak activity.
\end{abstract}

Results: To address this issue, we have developed a regulation strategy that includes feedback amplification of gene expression along with a differentially suppressible tetracycline regulated expression system (DiSTRES). By differentially suppressing expression of the tetracycline-regulated transcriptional activator (tTA) and silencer (tTS) genes based on the cell origin, this leads to the activation and silencing of the TRE promoter, respectively. In vitro transduction of $\mathrm{LNCaP}$ cells with Ad/GFP DisTRES lead to GFP expression levels that were over 30-fold higher than Ad/CMV-GFP. Furthermore, Ad/FasL-GFP ${ }_{\text {DisTRES }}$ demonstrated cytotoxic effects in prostate cancer cells known to be resistant to Fas-mediated apoptosis.

Conclusion: Prostate-specific regulation from the DiSTRES system, therefore, serves as a promising new regulation strategy for future applications in the field of cancer gene therapy and gene therapy as a whole.

\section{Background}

While the prostate cancer death rate has been decreasing steadily in the U.S. since the 1990s, prostate cancer remains the second leading cause of cancer death in men, with an estimated 27,050 deaths predicted to occur in 2007 [1]. When the disease is confined to the prostate, it can be cured by radical prostatectomy or irradiation therapy. However, there are no curative therapies for locally advanced, recurrent, or metastatic diseases. There is, therefore, a need to investigate alternative treatment strategies to improve these outcomes. One such approach is the use 
of cytotoxic gene therapy vectors directed against prostate cancer cells.

Several prostate cancer gene therapy strategies have been or are currently being evaluated in clinical trials [2]. These treatments have been well tolerated and have shown some indications of biological activity. In 2004 and 2005, the Chinese State Food and Drug Administration (SFDA) approved the first gene therapy-based products for cancer treatment: Gendicine (Sibiono GeneTech Co.) and H101 (Sunway Biotech Co.) $[3,4]$. The effectiveness of these two adenovirus-based products are quite encouraging for similar vectors being developed in the US, Advexin (Introgen) and ONYX-015 (Onyx Pharmaceuticals).

The ideal vector for prostate cancer gene therapy would be one that is both prostate-specific yet still elicits highly induced expression of the therapeutic gene. Previously, we developed and characterized a novel gene therapy regulation system known as the positive feedback loop with prostate specificity, or PFLPS, regulation system [5]. This system initiated a positive feedback loop of gene expression specifically in cells of prostate origin while retaining prostate-specificity even at MOI as high as 1000 [5]. The PFLPS system was developed by making specific modifications of the Tet-off regulation system (originally developed by Dr. Hermann Bujard [6]) to include the prostatespecific ARR2PB promoter (originally developed by Dr. Robert J. Matusik [7]).

While the PFLPS regulation system worked well for inducing GFP expression, incorporation of the pro-apoptotic FasL-GFP fusion into the PFLPS system gave only modest levels of cytotoxicity (Woraratanadharm, unpublished). In an attempt to improve the cytotoxicity of our vector, we developed an alternative strategy for achieving amplified prostate-specific transcriptional regulation. This system, which we have named the differentially suppressible tetracycline regulated expression system, or DiSTRES, was incorporated into a replication-incompetent Ad vector deleted in E1, E3, and E4 (except for E4orf6), and is similar to PFLPS, as it incorporates positive feedback loop amplification of gene expression as a result of incorporation of the TRE-ARR2PB promoter. However, the DiSTRES regulation strategy differs from PFLPS in that it investigates an alternative mechanism for regulating gene expression by including additional transcriptional regulatory elements to differentially suppress transgene expression depending on the cell type transduced.

In this study, we describe the development and characterization of our new DiSTRES regulation system. The DiSTRES system demonstrated highly induced, prostatespecific gene expression when incorporated into a complex Ad vector. In the presence of dihydrotestosterone
(DHT), these levels could be induced to levels up to 30 times higher than that of the CMV promoter and up to 10 times higher than our non-specific tet-regulated control. In addition, when FasL-GFP expression was mediated by the DiSTRES system, this vector demonstrated prostatespecific cytotoxicity, even in the FasL-resistant LNCaP cell line. Prostate-specific regulation from the DiSTRES system, therefore, serves as a promising new regulation strategy for future applications in the field of cancer gene therapy and gene therapy as a whole.

\section{Results \\ Design of the Differentially Suppressible Tetracycline Regulated Expression System (DiSTRES)}

The Tet-off system was originally designed by Hermann Bujard's group [6]. In this system, the tetracycline-regulated transcriptional activator protein (tTA) was developed to have binding affinity for a tandem repeat of DNA sequences known collectively as the tetracycline-responsive element (TRE). Binding of tTA to the TRE causes transcriptional activation of downstream promoters. The addition of tetracycline or its analog, doxycycline, to the system causes the tTA to lose its affinity for the TRE, and therefore, results in a loss of transcriptional activation.

Bujard's group also developed an opposing system, which utilizes the tetracycline-regulated transcriptional silencer protein (tTS) [8]. Like tTA, tTS binds to the TRE and loses its affinity for the TRE in the presence of tetracycline or doxycycline. Opposite from tTA, however, binding of tTS to the TRE leads to transcriptional silencing (not activation) of downstream promoters. Therefore, differential expression of tTA in certain contexts and tTS in other contexts can be utilized to either turn "on" or "off" a particular gene's expression, respectively.

Our first generation Tet-regulated, prostate-specific (PS/ TR) vector [9] was developed by a slight modification of the Tet-off system in which the tTA was driven by the prostate-specific ARR2PB promoter instead of by the CMV promoter (see Fig. 1). This vector lacked the positive feedback loop incorporated into both the PFLPS and DiSTRES vectors. It also demonstrated a low level of detectable transgene expression in non-prostate cells. We believed this to be the result of a slight induction of the TRE promoter even in the absence of tTA expression. To improve this system, we developed the PFLPS system.

In the PFLPS regulation system, we cloned the TRE upstream of the ARR2PB promoter to develop a prostatespecific, tTA-inducible promoter known as the TREARR2PB promoter (see Fig. 1). Using the TRE-ARR2PB promoter to drive the expression of both tTA and GFP led to a positive feedback loop which was only activated in prostate cells [5]. This activity was effective at inducing 


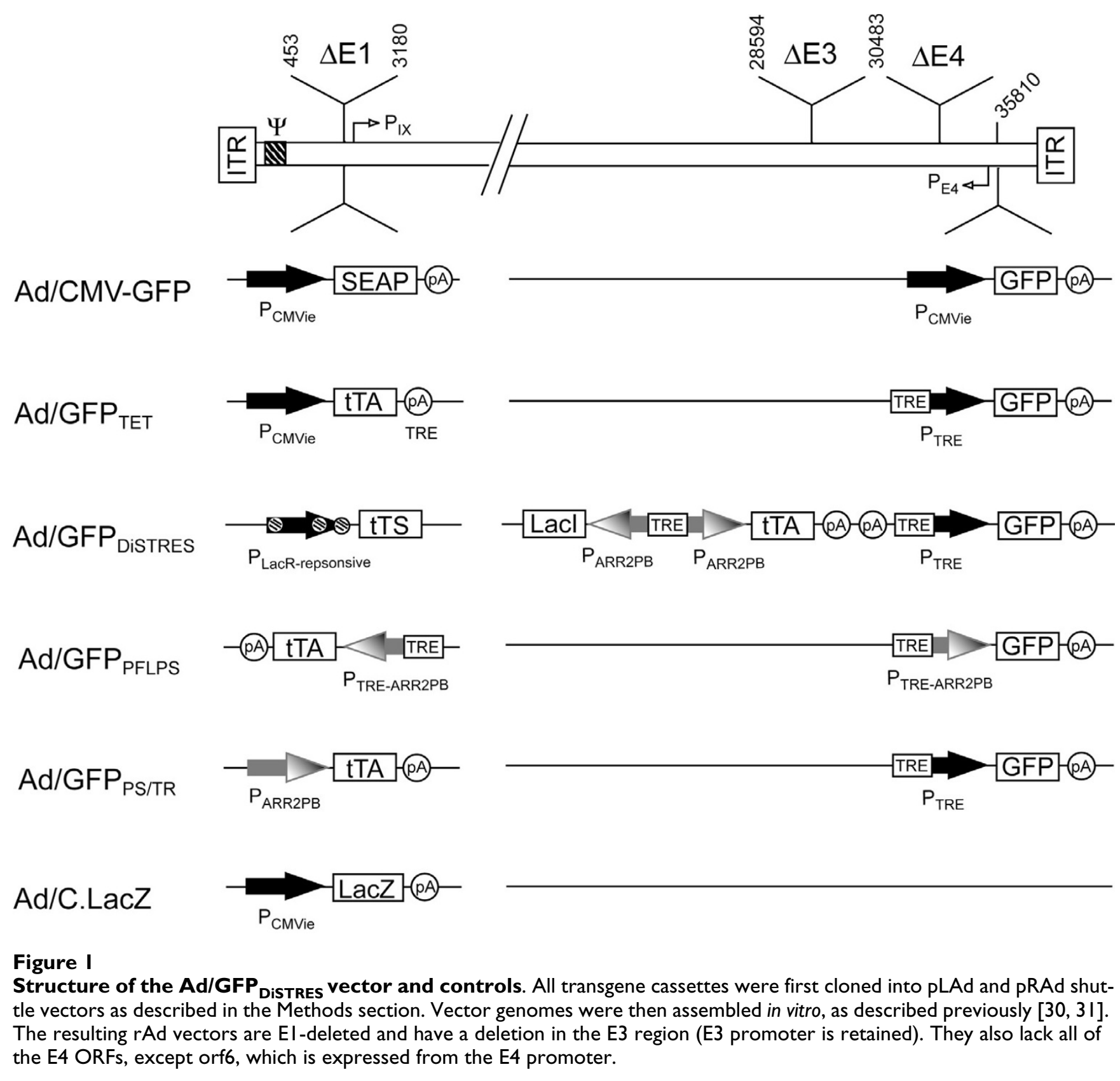

GFP expression, but FasL-GFP induction was somewhat modest.

In order to amplify prostate-specific expression further, we developed the novel DiSTRES regulation system. In this system we added two transcriptional silencer proteins, the tTS protein and the Lac repressor (LacR) protein, to the positive feedback loop design in order to differentially suppress gene expression depending upon the cell type transduced. The conceptual difference between PFLPS and DiSTRES is that in DiSTRES, the gene of interest is driven by the original TRE promoter instead of the prostate-specific ARR2PB-TRE promoter. From our previous experience with PS/TR, we found that the original TRE promoter often has some low level activity even in the absence of tTA expression. To counteract this activity, we added the tTS suppressor to decrease background transgene activation in non-target cells. However, in the setting of a prostate cell, tTS is not induced due to negative regulation from the LacR repressor (see Figs 1 and 2).

The design of the DiSTRES regulation system as cloned into an Ad5 vector deleted in E1, E3, and E4 (except for E4orf6) is depicted in Fig. 1. Control Ad vectors include 

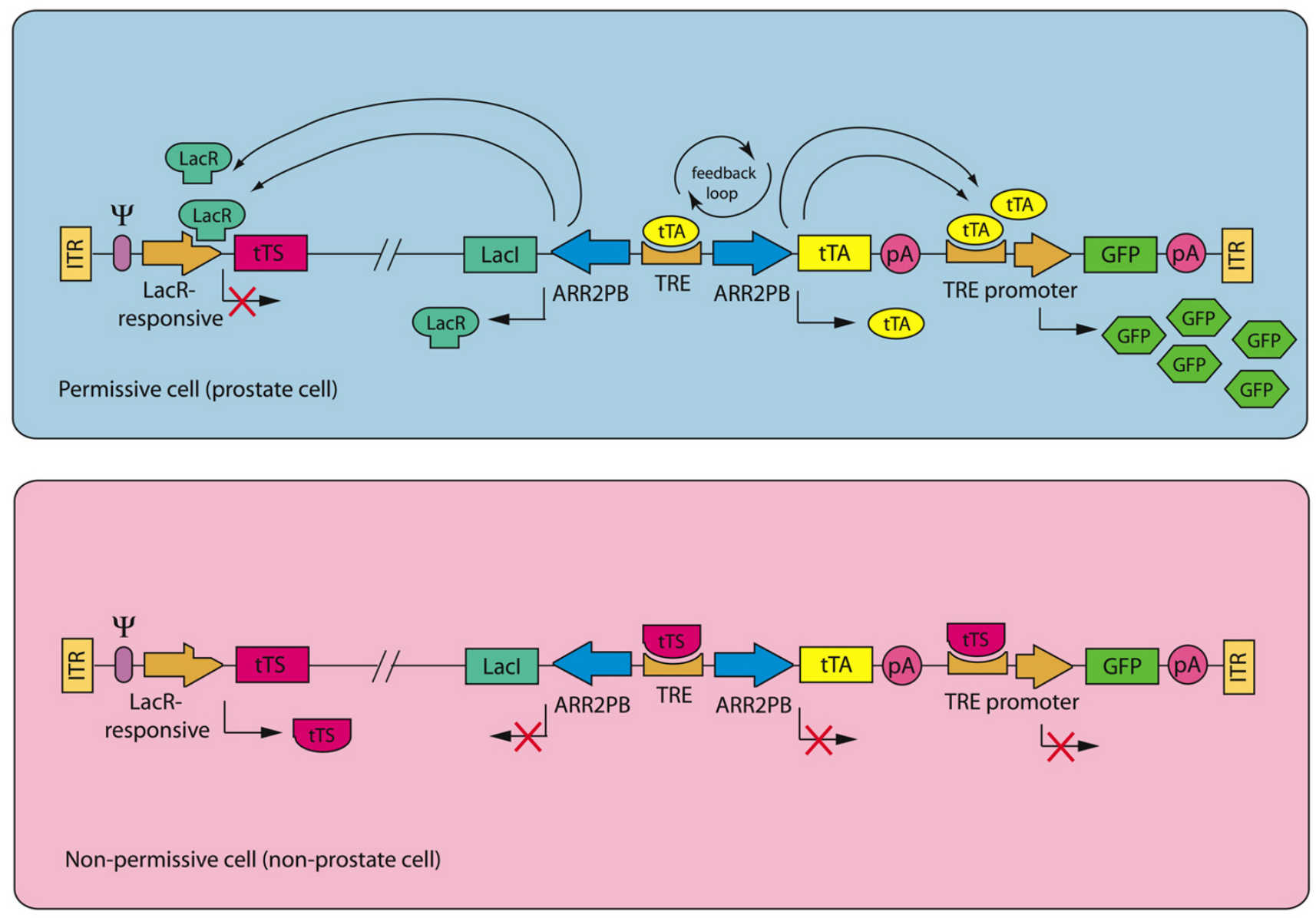

\section{Figure 2}

Mechanism of action of the Ad/GFP Distres $_{\text {vector. Mechanism of action of the Ad/GFP }}$ DisTRES vector when transduced into a prostate cell (top panel). We hypothesize that the following sequence of events would occur in the prostate cell: (I) Both the tTA and the Lacl genes would be induced, as a result of activation of the prostate specific TRE-ARR2PB promoters that drive the expressions of these genes; (2) Expression of tTA would then lead to transcriptional activation of the gene of interest (e.g., GFP), through binding of tTA to the TRE promoter; (3) The tTA protein would also bind to the TRE within its own TREARR2PB promoter, thereby activating further transcription of itself and therefore establishing a positive feedback amplification loop of tTA expression; (4) Meanwhile, the LacR protein would bind to the LacR-responsive promoter of the tTS gene, thereby leading to suppression of $t T S$ gene transcription; and (5) Finally, the tTA-driven amplification loop would lead to further expression of both the gene of interest and the LacR (and subsequently further repress the tTS). Mechanism of action in non-prostate cells (bottom panel). In the non-prostate cell, we propose the following scenario: (I) Because the TRE-ARR2PB promoter is prostate-specific, neither the tTA nor the LacR proteins would be expressed; (2) In the absence of the LacR protein, the LacRresponsive promoter acts essentially like its constitutively active parental promoter (the CMV promoter). As a result, the $t T S$ gene is now actively transcribed; and (3) Expression of the tTS protein would then lead to the transcriptional silencing of all TRE-regulated promoters, and therefore, the gene of interest (GFP), tTA and LacR would all be suppressed upon binding of the tTS to the TRE's within their respective promoters. Note: Tetracycline and/or doxycycline are not added to this system. Adding these drugs would act to negate the effects of the differential regulation of tTA versus tTS. The result would be basal expression of GFP in both cell types, and therefore, a loss in prostate-specificity. 
$\mathrm{Ad} / \mathrm{GFP}_{\mathrm{TET}}$, which expresses GFP under the control of the traditional tet-off regulatory system, Ad/CMV-GFP, which expresses GFP under the control of the strong, constitutively active CMV promoter, and Ad/C.LacZ, which expresses $\beta$-galactosidase under the control of the $\mathrm{CMV}$ promoter. The designs of our earlier generation PS/TR and PFLPS vectors are also shown.

In the DiSTRES vector, three transgene cassettes were cloned into the right-end of the genome, which includes the following: (1) TRE-ARR2PB promoter driving Lac repressor ( $\mathrm{LaCI}$ ) gene expression, cloned in reverse orientation, (2) ARR2PB promoter driving tTA expression, cloned just downstream of the TRE-ARR2PB.LacI cassette such that the TRE has bi-directional activity on both the LacI and tTA genes, and (3) original TRE promoter controlling GFP expression, cloned downstream of the ARR2PB.tTA cassette (see Fig. 1). In addition, a transgene cassette containing a newly developed LacR-responsive promoter (see Methods) was cloned into the left-end of the genome and controlled $t$ TS gene expression (see Fig. $1)$.

The cloning capacity of our E1/E3/E4(except orf6)-deleted Ad vector is approximately $7.5 \mathrm{~kb}$. Therefore, several strategic cloning measures had to be taken in order to conserve sufficient space to include all four transgene cassettes into a single complex adenovirus vector (see Methods). In addition, special consideration was made in the construction of this complex rAd vector based upon our previous findings regarding interference from the E1a enhancer. Because we previously had found that the basal activity of both the TRE and the ARR2PB promoters were significantly affected by interference from the E1a enhancer [10], we designed the Ad/GFP $P_{\text {Distres }}$ vector so that all TRE and TRE-ARR2PB promoters were away from the $\mathrm{E} 1$ region by placing them near the right ITR (Fig. 1). Meanwhile, the transgene cassette containing the LacRresponsive promoter driving tTS expression was cloned near the left ITR (Fig. 1). The theoretical mechanism of action of the DiSTRES regulation system is diagrammed in Fig. 2.

\section{Levels of prostate-specific expression from Ad-delivered DiSTRES are greater than that induced by either the CMV promoter or tet-regulated controls}

In order to determine the prostate-specificity of the $\mathrm{Ad} /$ $G F P_{\text {DisTRES }}$ vector, two prostate cancer cell lines, LNCaP and PC3/AR, and two non-prostate cell lines, HeLa and $\mathrm{U} 251 \mathrm{MG}$, were chosen for in vitro analysis. Since the ARR2PB promoter is known to be inducible by androgen (e.g., dihydrotestosterone; DHT) [7], the LNCaP cell line was chosen specifically because it is one of the few prostate cancer cell lines available that express functional androgen receptor (AR). The PC-3 cell line is known to be
AR negative, and therefore, an AR stable transfectant PC-3 cell line (PC3/AR) was chosen [11] for the Ad/GFP DiSTRES characterization studies. In order to directly compare vector activity in prostate versus non-prostate cells, all cell types were infected in the presence of DHT, even though DHT would not likely be present under physiological tissues.

For in vitro analysis, both prostate and non-prostate cell lines were infected with $\mathrm{Ad} / G F P_{\text {DiSTRES }}$ vector and controls (Fig. 3). Due to differing transduction efficiencies among cell lines, each cell type was infected at an optimized MOI, based on pilot dose response studies conducted with the $\mathrm{Ad} / \mathrm{GFP}_{\mathrm{TET}}$ vector. Data are represented as fold GFP expression, setting infection with the Ad/CMV-GFP control vector at 1 . As demonstrated in Fig. 3, Ad/GFP $P_{\text {DisTRES }}$ vector induced high levels of GFP expression in the prostate cancer cell lines without a loss in prostate specificity. In PC3/ AR cells, the Ad/GFP $P_{\text {DisTRES }}$ vector induced GFP expression to levels similar to the non-specific, constitutively active Ad/CMV-GFP control. Remarkably, GFP induction by the $\mathrm{Ad} / G F P_{\text {DisTRES }}$ vector in LNCaP cells was not only significantly higher than that seen with Ad/CMV-GFP ( $\mathrm{p}=$ 0.043 ) but also significantly amplified, even in comparison to the Ad/GFP $P_{\text {TET }}$ vector ( $\left.\mathrm{p}=0.038\right)$. In fact, the activity from $\mathrm{Ad} / G F P_{\text {DiSTRES }}$ was over 30 -fold higher than $\mathrm{Ad} /$ CMV-GFP and over 10-fold higher than the highly induced tet-regulated $\mathrm{Ad} / G F P_{\mathrm{TET}}$ vector, when transduced in LNCaP cells. Meanwhile, the levels of GFP expression in the HeLa and U251MG cells were similar to background, with a low level of GFP expression seen in HeLa cells.

\section{The Ad/GFP DisTRES $_{\text {vector demonstrates improved }}$ prostate-specific GFP induction compared to the earlier generation, Ad/GFP PSITR $_{\text {and Ad/GFP }}$ PFLPS vectors}

We wanted to determine whether the DiSTRES system had improved upon our earlier generation designs, the PS/TR and PFLPS systems. In order to conduct a comparative analysis of these three prostate-specific regulation systems, we infected LNCaP and U251MG cells in parallel with $\mathrm{Ad} / \mathrm{GFP}_{\mathrm{PS} / \mathrm{TR}}, \mathrm{Ad} / \mathrm{GFP}_{\text {PFLPS }}$ Ad/GFP DiSTRES' Ad/ $\mathrm{GFP}_{\mathrm{TET}}$, or Ad/C.LacZ and assayed for GFP expression (Fig. 4). As demonstrated in Fig. 4, the activity of the Ad/GFP $\mathrm{PS} /$ ${ }_{\mathrm{TR}}$ vector (which lacks the positive feedback loop) was less than that induced by either Ad/GFP PFLPS $_{\text {or }}$ Ad/GFP DiSTRES in LNCaP cells at all MOI's tested. Overall, the Ad/GFP TRES vector demonstrated the highest levels of prostate-specific GFP expression at all MOI's tested. In addition, the $\mathrm{Ad} / \mathrm{GFP}_{\mathrm{PS} / \mathrm{TR}}$ vector demonstrated more non-specific expression in U251MG than either Ad/GFP PFLPS $_{\text {or } \mathrm{Ad} /}$ $\mathrm{GFP}_{\text {DiSTRES }}$, except at MOI 1000, where the Ad/GFP $\mathrm{GiSTRES}_{\text {S }}$ vector loses some of its specificity. Finally, Fig. 4 visually demonstrates the difference in GFP induction and specif- 


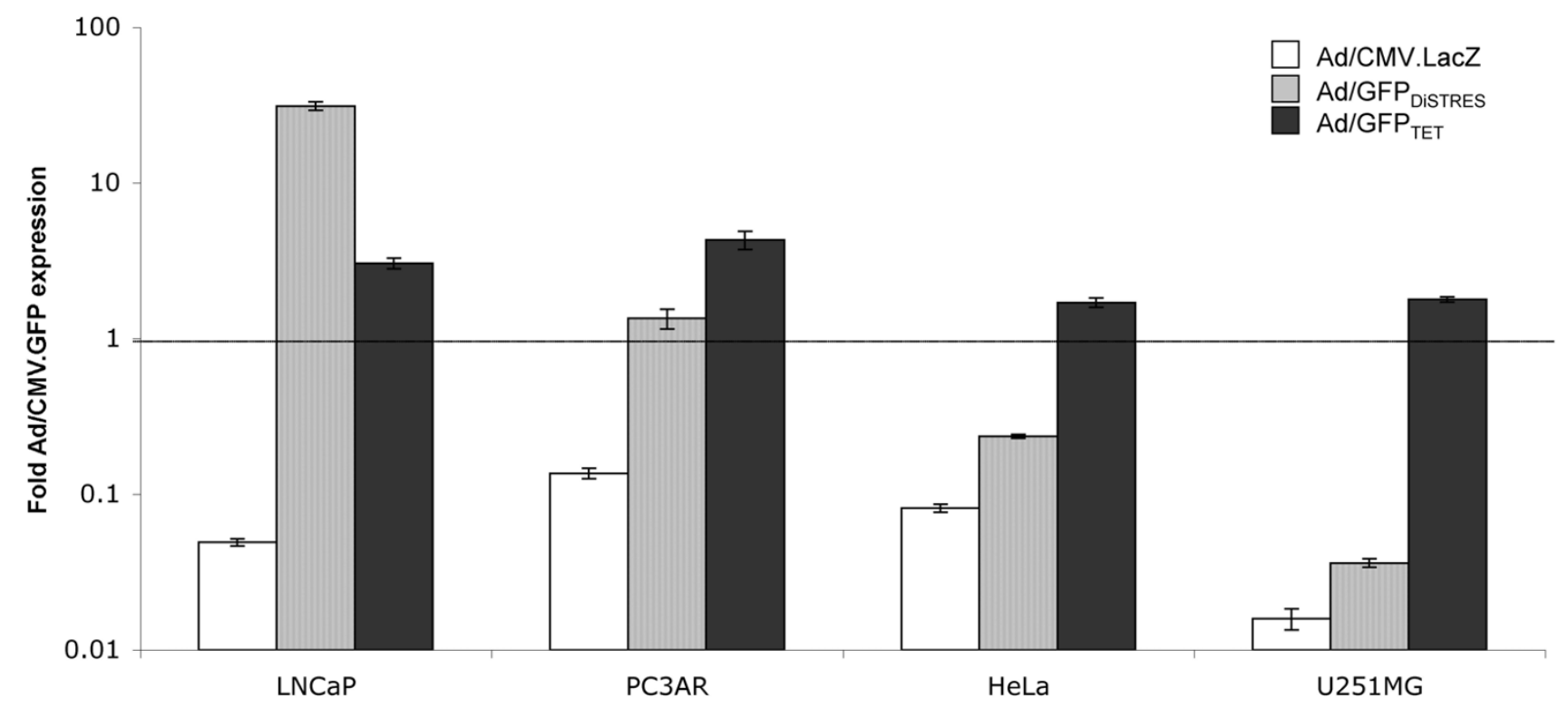

Figure 3

Comparison of DiSTRES- and CMV-mediated gene expression. LNCaP, PC3AR, HeLa and U25IMG cells were seeded at I.25 × $10^{4}$ cells/well in 96-well plates and infected with complex Ad vectors at MOI 30, 200, 200, and 50, respectively, in the presence $30 \mathrm{nM}$ DHT. 2 days post-infection, cell lysates were assayed for GFP fluorescence. Infection with Ad/ C.LacZ served as a negative control infection. Results are displayed as fold expression, setting GFP fluorescence from Ad/ CMV.GFP infection at I for each cell line. Due to differing transduction efficiencies among cell lines, each cell type was infected at an optimized $\mathrm{MOI}$, based on pilot dose response studies conducted with the Ad/GFP $P_{\mathrm{TET}}$ vector. MOI values were based on $\mathrm{IU} / \mathrm{ml}$. *p $<0.05$ compared to Ad/CMV.GFP. †p $<0.05$ compared to Ad/GFP $\mathrm{TET}_{\text {. }}$

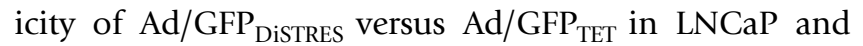
U251MG cells at MOI 100.

\section{DiSTRES-mediated FasL-GFP cytotoxicity is prostate- specific}

In order to characterize the DiSTRES regulation system in the context of a prostate cancer therapeutic, we first subcloned the FasL-GFP fusion gene in the place of the GFP gene within $\mathrm{Ad} / G F P_{\text {Distres, }}$ resulting in the Ad/FasL-GFPDisTRES vector. We then infected the same panel of prostate and non-prostate cell lines described in Fig. 3 with Ad/ FasL-GFP $P_{\text {DistREs }}$ vector and controls and assayed for resultant cell viability (see Fig. 5). Since each cell type showed varying sensitivities to adenovirus-delivered FasL-GFP, we infected each cell type at MOI values determined during pilot studies to induce maximal cytotoxicity in response to Ad/FasL-GFP ${ }_{\mathrm{TET}}$ control.

The cytotoxicity of all of the prostate-specific vectors was prostate-specific, as there was increased cell viability in the U251MG and HeLa cells when compared to the Ad/FasL$G F P_{\mathrm{TET}}$ control. In LNCaP, cell viability in Ad/FasL-GFP $P_{\text {Dis- }}$ TRES-transduced cells was greatly reduced although not to the same degree as our positive control for apoptosis, Ad/
FasL-GFP $P_{\text {TET }}$. In PC3AR, similar levels of cell viability were seen among the three prostate-specific vectors.

In comparison to the PS/TR and PFLPS vectors, the DiSTRES vector demonstrated the highest level of cytotoxicity in LNCaP cells. However, the cytotoxic activity of Ad/FasL$G F P_{\text {DiSTRES }}$ compared to mock infection was not statistically significant. Although the cell viability studies did not reveal a statistical difference between Ad/FasL-GFP ${ }_{\text {DisTrEs }}$ and control, both prostate cancer cell types did demonstrate the typical cell-rounding morphology as a result of

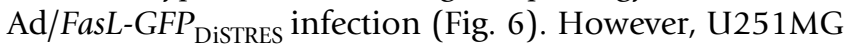
seemed to be somewhat affected by Ad/FasL-GFP ${ }_{\text {DisTRES }}$ infection, as well.

\section{Discussion}

A wide range of gene therapy vector approaches is being investigated as potential cancer therapeutics including manipulation of cell cycle control, apoptosis strategies, suicide gene therapy, tumor-selective replicating virus vectors, angiogenesis therapy and immunotherapy. Recent successes in cancer gene therapy include the approvals of the Ad/p53 vector known as Gendicine from SiBiono GeneTech Co. and the oncolytic Ad vector known as H101 
a

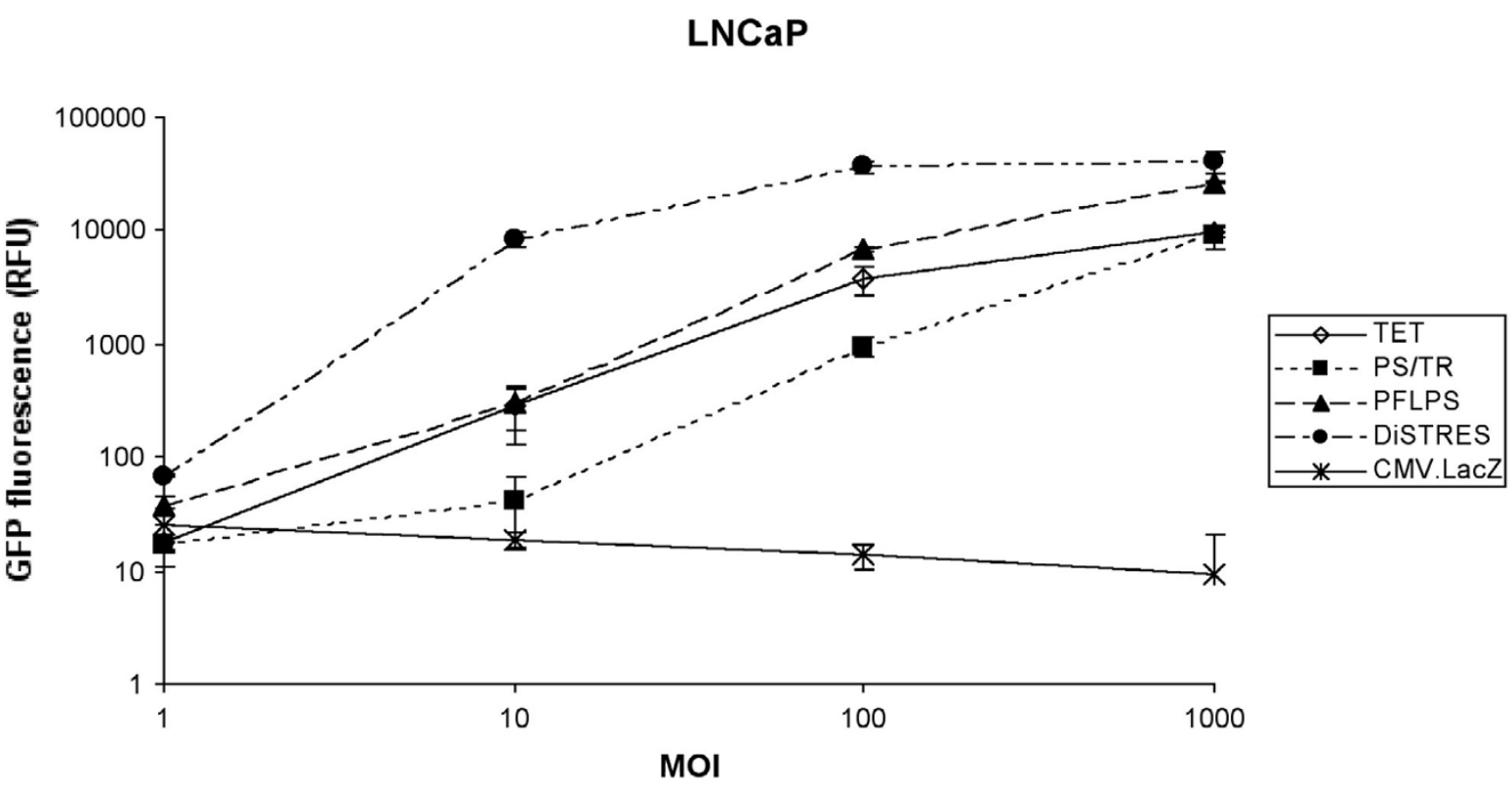

b

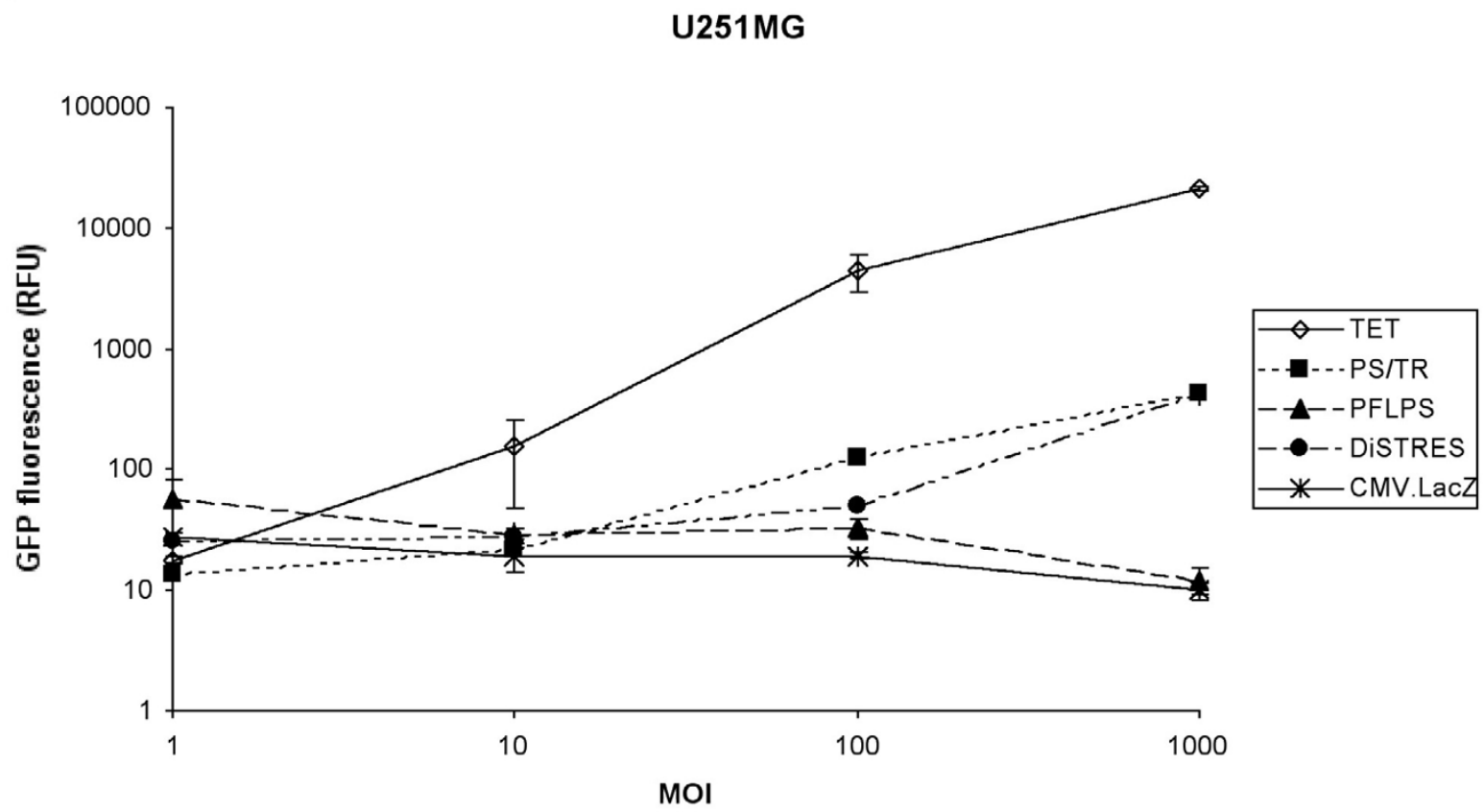

Figure 4

Ad/GFP DistRes demonstrates specificity for prostate cells, decreased activity in non-prostate control cells, and improves upon earlier vector designs. GFP fluorescence of (a) LNCaP cells and (b) U25IMG cells. LNCaP and U25IMG cells were seeded at $1.25 \times 10^{4}$ cells/well of a 96-well plate and infected with Ad/GFP TRES, or Ad/C.LacZ (negative control) in the presence of $30 \mathrm{nM} \mathrm{DHT}$ at MOI I, 10, 100, or 1000. 2 days post-infection, cell lysates were assayed for GFP fluorescence. RFU: relative fluorescence units. MOI values were based on IU/mI. 


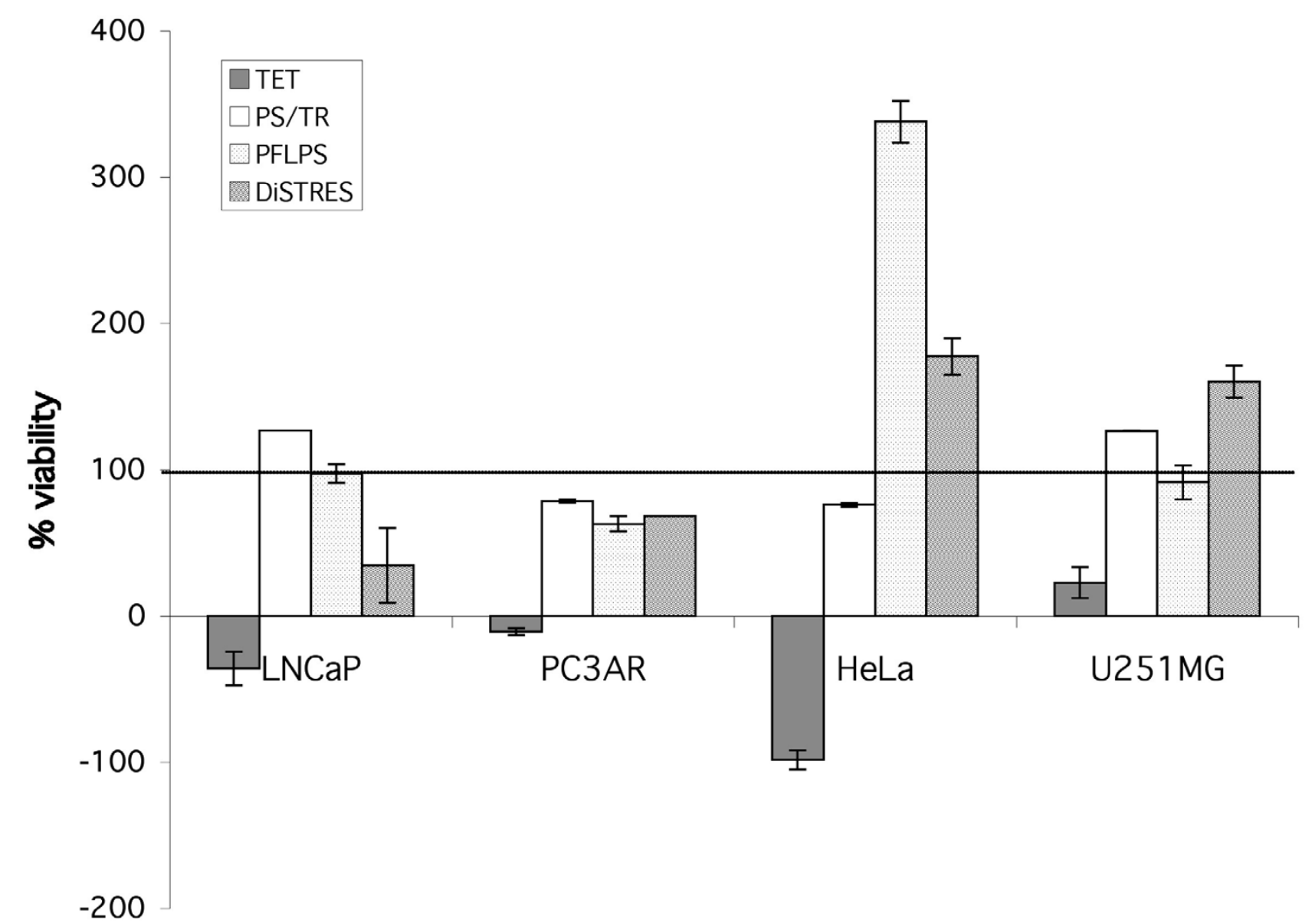

\section{Figure 5}

Ad/FasL-GFP DiSTRES demonstrates preferential cytotoxicity in prostate cells. LNCaP, PC3AR, U25IMG, and HeLa cells were seeded at $1.25 \times 10^{4}$ cells/well in a 96-well plate and infected with Ad/FasL-GFP TET, Ad/FasL-GFP $_{\text {PS/TR }}$, Ad/FasL-GFP $_{\mathrm{P} \text { - }}$ FLPS , Ad/FasL-GFP ${ }_{\text {DiSTRES }}$, or I $\times$ HBS (mock) in the presence of $30 \mathrm{nM} \mathrm{DHT.} \mathrm{LNCaP,} \mathrm{PC3AR,} \mathrm{U25IMG,} \mathrm{and} \mathrm{HeLa} \mathrm{were} \mathrm{infected}$ at $\mathrm{MOI} 10,5,5$, and 2.5, respectively. Three days post-infection, cells were fixed with methanol and then assayed for cytotoxicity using crystal violet assay. Since each cell type showed varying sensitivities to adenovirus-delivered FasL-GFP, we infected each cell type at MOI values determined during pilot studies to induce maximal cytotoxicity in response to Ad/FasL-GFP trol. Percent viability was calculated by dividing the mean absorbance of each sample by the mean absorbance of $\mathrm{I} \times \mathrm{HBS}$ mock infection for each cell line and then multiplying by $100 \%$. MOI values were based on pfu/ml. Horizontal line delineates $100 \%$ viability.

from Sunway Biotech Co. for clinical use in China [3,4]. The activity of both of these adenovirus-based vectors takes advantage of the fact that over $50 \%$ of all cancers have mutations in p53. Additionally, evidence from Onyx's ONYX-015 and Sunway's H101 vectors appear to indicate that these oncolytic vectors also have activity in non-p53 mutant cancer cells as well [3].

When designing gene therapy vectors for the treatment of cancer, along with selection of therapeutic transgene, an equally important aspect to take under consideration is how to target gene expression. This is particularly important considering that the two initial phases of clinical characterization (Phase I and II clinical trials) focus on safety. The cancer gene therapy vector most likely to demonstrate a significant clinical result will be one that initiates a large therapeutic index (i.e., high potency against malignant cells), while keeping toxicity to normal tissues at a minimum. The use of an amplified feedback loop strategy to tightly regulate yet highly induce gene expression may be key to the development of additional cancer therapeutic vectors. 
Tet

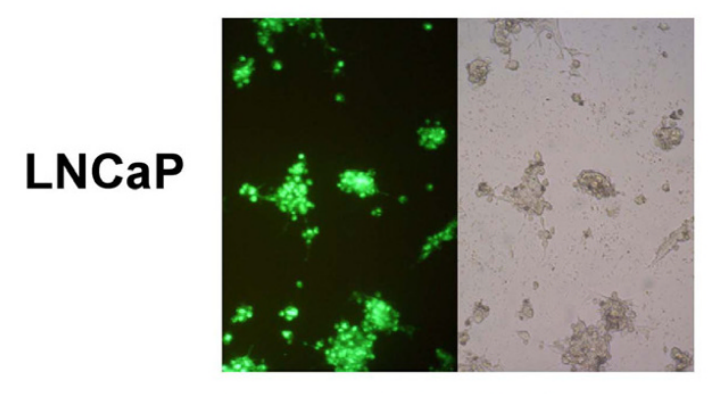

PC3AR
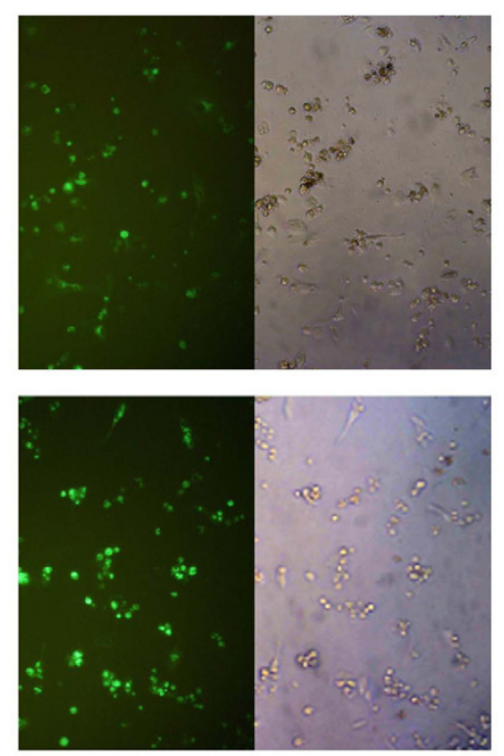

DiSTRES
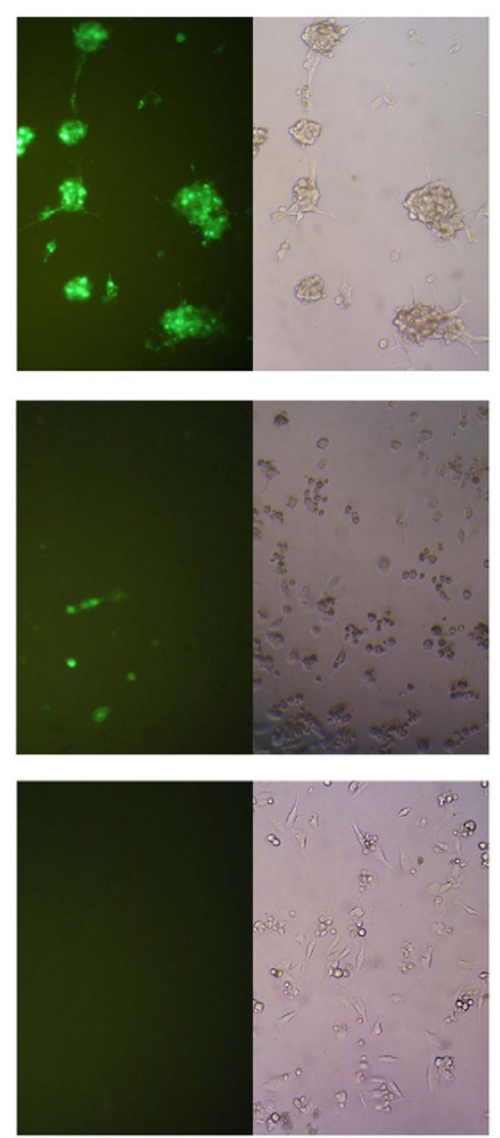

LacZ
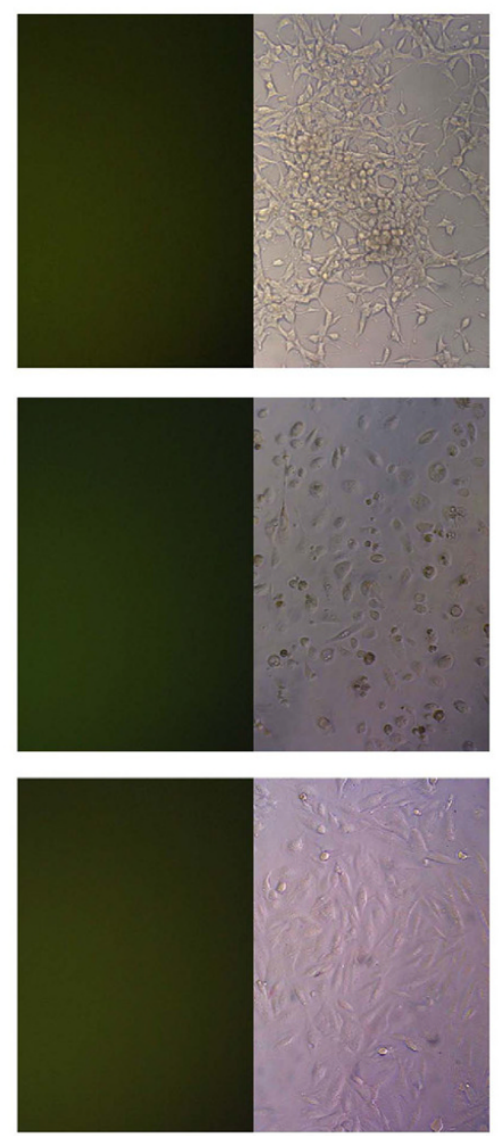

\section{Figure 6}

Ad/FasL-GFP ${ }_{\text {DiSTRES }}$ demonstrates prostate-specific cytotoxicity as indicated by rounded morphology of prostate cancer cells. LNCaP, PC3AR, and U25IMG cells were seeded at and infected as described in Fig. 5. LNCaP, PC3AR, and U25IMG were infected at MOI 10, 5, and 5, respectively. Two days post-infection, cells were visualized using Axiovert-25 fluorescent microscope with FITC filter set and photos taken with Pixera digital camera at I00x magnification. Photos on the left were taken under UV light. Photos on the right were taken under bright field setting. MOI values are based on pfu/ml.

In this study, we have constructed and characterized a novel transcriptional regulation system that incorporates both an amplification feedback loop, as well as two tissueselective repressor elements, which differentially suppress specific transcriptional events, depending upon the cell type transduced. This differentially suppressible tetracycline regulated expression system (DiSTRES) demonstrated prostate-specific transgene induction, as the Ad/ $\mathrm{GFP}_{\text {DiSTRES }}$ vector was found to induce GFP expression levels in PC3/AR cells to levels similar to that of the CMV promoter, a promoter which is well-recognized as a strong, constitutively active promoter of non-specific gene expression. Moreover, the $\mathrm{Ad} / \mathrm{GFP}_{\text {Distres }}$ vector induced GFP expression levels in LNCaP cells to levels that significantly exceeded those of both the CMV promoter as well as the tet-regulated system. This induction by $A d / G P_{\text {Dis- }}$
TRES was approximately 30 times the activity of Ad/CMVGFP and approximately 10 times the activity of $\mathrm{Ad} /$ $\mathrm{GFP}_{\mathrm{TET}}$. Additionally, the Ad/GFP $\mathrm{DiSTRES}_{\text {vector retained }}$ specificity in the two non-prostate cell line controls, HeLa and U251MG. Levels of GFP expression from the Ad/GFPDiSTRES vector, upon transduction of these non-prostate cell lines, were similar or slightly higher than background.

Finally, although LNCaP cells are known to be resistant to FasL-mediated apoptosis, the Ad/FasL-GFP ${ }_{\text {DisTrEs }}$ vector demonstrated cytotoxic effects in LNCaP and somewhat modest effects in PC3AR cells. This overcoming of FasL resistance was seen previously with our tet-regulated Ad/ FasL-GFP ${ }_{\text {TET }}$ vector [12], and we believe it is due to an overexpression of FasL-GFP overcoming a certain threshold in these resistant cells. Once the cells are saturated 
with FasL-GFP, the cell then appears to become susceptible to the FasL-mediated apoptosis.

A two-step transcriptional amplification (TSTA) system has been described which utilizes a Gal4-VP16 fusion protein instead of tTA for amplification of gene expression [13-17] and is similar to our previous PS/TR system [9]. In transfection experiments, Zhang et al. demonstrates a 10fold increase in prostate-specific luciferase expression in LNCaP, compared to CMV [17]. In another report, Block et al. claims an amplification of up to 590-fold of luciferase expression in SKCO1 cells compared to CMV [13]. Similar results have not been repeated by other groups using the TSTA system. The specificity of Block et al's vector, however, was greatly compromised as a result. In their negative control cell line, HepG2, their Ad.Muc bin $_{\text {-luc vec- }}$ tor demonstrated 7-fold higher gene expression than CMV at MOI 1 . The authors do not explain the reasoning for this very high background activity in non-target cells [13]. Such increased expression in non-target cells could potentially be mitigated utilizing a system similar to DiSTRES. However, it is difficult to compare the two systems since many papers do not describe the activity of the TSTA in non-target cells. Further study will need to be conducted to truly compare the two systems.

The DiSTRES transcriptional regulation system has three characteristics that separate it from other regulation systems published in the literature: (1) differential expression of two transcriptional repressor proteins (tTS or LacR) depending on the cell type transduced; (2) incorporation of a positive feedback amplification loop of prostate specific gene expression; and (3) the cloning of the entire system into a single complex recombinant Ad vector, thus preventing the need for co-infection with two or more separate Ad vectors. In fact, most Ad vectors published in the literature (gutless Ad vectors included) contain only a single transgene cassette. This, therefore, makes the progressiveness of the Ad/GFP ${ }_{\text {DistRES }}$ and Ad/ FasL-GFP $_{\text {DistRES }}$ vectors rather uncommon as both of these vectors each contained four expression cassettes.

Application of the DiSTRES regulation system is not restricted to only the gene therapy treatment of prostate cancers. Its complex transcriptional regulation concept could be transferred to other tissue types by simply incorporating different tissue-specific promoters, thereby expanding its potential utility to include gene therapy of other cancers and molecular genetic applications other than cancer, such as the gene therapy treatment of genetic disorders, development of gene-based vaccines expressing immunogenic bacterial or viral antigens, and development of new transgenic mouse models that require highly induced, organ-restricted expression of a particular gene of interest. Finally, the effective transcriptional regulation afforded by DiSTRES could be combined with current methods of transductional regulation including manipulation of Ad fiber knob [18-24] and use of bi-specific antibodies [25-29] to further improve the targeting of gene therapy vectors to specific cell types and therefore increase the specificity and the safety of the vectors.

\section{Conclusion}

We have developed and characterized a novel transcriptional regulatory system that demonstrates highly induced, prostate-specific expression that retains its tissue-specificity. Such a regulation system could be potentially modified to include tissue- or cancer-specific promoters in the place of the ARR2PB promoter as well as any desired therapeutic transgene and thus is ideal for several molecular genetic and gene therapeutic applications that require highly induced, organ-restricted expression of a particular gene of interest. This transcriptional regulation can also be combined with transductional regulation systems to increase the specificity and the safety of current gene therapy vectors. The DiSTRES regulation system, therefore, serves as a promising new approach for the transcriptional regulation of therapeutic genes for future molecular genetic and therapeutic applications.

\section{Methods \\ Cell lines}

HEK293 (human embryonic kidney) and LNCaP (prostate cancer) cells were obtained from American Type Culture Collection (ATCC; Manassas, VA). U343MG and U251MG (brain tumor) cell lines were obtained from the Brain Tumor Research Center Tissue Bank (Dept. of Neurological Surgery, UCSF, San Francisco, CA). PC3/AR (the human prostate cancer cell line, PC-3, stably transfected with human androgen receptor cDNA) was generously provided by Kerry L. Burnstein. All cell lines were maintained in media supplemented with $10 \%$ cosmic calf serum (CCS; HyClone, Logan, UT), with HEK293 being maintained in DMEM, LNCaP being maintained in RPMI, PC3/AR being maintained in RPMI containing $350 \mu \mathrm{g} / \mathrm{ml}$ active G418, and U343MG and U251MG being maintained in MEM.

\section{Construction of plasmids vectors}

The pUHD 10-3 (containing the TRE promoter), the pUHD 15-1 (containing the tTA gene), and the pUHS 6-1 (containing the $t T S$ gene) plasmids were generously provided by Hermann Bujard. The ARR2PB $(0.45 \mathrm{~kb})$ promoter was developed in the laboratory of Robert $\mathrm{J}$. Matusik, who contributed the PARR2PB.PolI.TRZ-SK vector. Construction of pLAd-CMV, pLAd-mcs and pRAdT.GFP vectors has been described previously [12].

For construction of the DiSTRES vectors, first, the tTA gene and BGH polyA were excised as a single fragment from 
pUHD 10-3.B (a modified version of pUHD 10-3 which includes a polyA from BGH in place of the original SV40 polyA) and subcloned in place of the SEAP gene within the pLAd(2Pb.SP) r plasmid (described previously) [10], resulting in the pLAd(2Pb.tTA.B $)_{\mathrm{r}}$ vector. Next, the ARR2PB.tTA.B cassette from pLAd(2Pb.tTA.B) $)_{\mathrm{r}}$ was subcloned upstream of the TRE.GFP cassette of pRAd ${ }^{2}$ T.GFP.B to obtain the $\operatorname{pRAd}^{2}(2 \mathrm{~Pb} . t T A . B) B(T . G F P . B)$ plasmid. Next, the LacI gene was PCR amplified from the pCMVLacI plasmid (Stratagene) and then subcloned in the place of the GFP gene within the pRAd ${ }^{2}$ T2Pb.GFP.B plasmid (described previously) [5], resulting in the pRAd $^{2}$ T2Pb.LacI.B plasmid. Finally, the T2Pb.LacI cassette was subcloned in reverse orientation upstream of the ARR2PB.tTA cassette within $\operatorname{pRAd}^{2}(2 \mathrm{~Pb} . t T A . B) B(T . G F P . B)$, leading to construction of the pRAd ${ }^{2}(\mathrm{~T} 2 \mathrm{~Pb} . L a c I)_{\mathrm{r}}(2 \mathrm{~Pb} . t T A . B) \mathrm{B}(\mathrm{T} . G F P . B)$ right-end shuttle plasmid of DiSTRES. By placing the T2Pb.LacI cassette in reverse and upstream of he ARR2PB.tTA cassette, this resulted in both the LacI and the tTA genes sharing a TRE, thus conserving on much needed space, as well as placing both genes under the control of TRE-ARR2PB promoters.

The LacR-responsive promoter was developed by PCRamplifying the CMV promoter using oligos containing lac operator $\left(\mathrm{o}_{\mathrm{i}}\right)$ sequences to modify the CMV promoter. These oligos were designed to introduce a single lac operator near the $5^{\prime}$ end of $\mathrm{CMV}$ as well as two lac operators flanking the TATA box near the 3 ' end of the promoter. The oligo sequences, 5'-TTTTTTTTTACTAGTGGAATTGTGAGCG CTCACAATTCCACATTAATAGTAATCAATTACGGGGTCATTAG-3' forward; and 5'TTTTTTTTTGGATCCTGTGGAATTGTGAGCGCTCACAAT TCCACATCGAAATTCCGCGGACCGGTCGCCACCAT-

GGTGAGCAAGGGCGAGGA-3' reverse, were used to construct the LacR-responsive promoter, using pcDNA3.1 (Invitrogen) as a template. The LacR-responsive promoter PCR fragment was then cloned in the place of the CMV promoter within the pUHS 6-1 plasmid to yield the pUHS $\mathrm{Co}_{\mathrm{i}} 2 . t T S . S$ plasmid. Finally, the $\mathrm{Co}_{\mathrm{i}} 2 . t T S$ cassette was subcloned into the pLAd-CMV plasmid in place of the CMV promoter, resulting in the pLAd.Co $\mathrm{o}_{\mathrm{i}} 2 . t T S$ left-end Ad shuttle plasmid vector.

It should be noted that the cloning capacity of our E1/E3/ E4(except orf6)-deleted Ad5 vector is approximately 7.5 $\mathrm{kb}$ and that the total size of the DiSTRES regulation system just fits or slightly exceeds this value ( $\sim 7.4 \mathrm{~kb}$ with GFP; $\sim 8.16 \mathrm{~kb}$ with FasL-GFP). Therefore, in order to conserve on space, both the tTS and the LacI genes were cloned into their respective shuttle plasmids without polyadenylation signals. PolyA sites were not required for these two particular transgene cassettes due to their orientations in relation to the deleted Ad genes within the Ad vector genome.
The polyA sites for the E1b and E4 genes can be utilized for the polyadenylation of the tTS and the LacI genes, respectively.

\section{Construction of recombinant adenoviral vectors}

Construction of Ad/C.LacZ and Ad/GFP $P_{\text {TET }}$ has been described previously [12]. The pRAd $^{2}(\text { T2Pb.LacI })_{\mathrm{r}}(2 \mathrm{~Pb} . t$ TA.B)B (T.GFP.B) plasmid was digested with SwaI and SpeI while the pLAd. $\mathrm{Co}_{\mathrm{i}} 2 . t T S$ plasmid was digested with SwaI and AvrII. The digested pLAd. $\mathrm{Co}_{\mathrm{i}} 2 . t T S$

and pRAd $^{2}(\text { T2Pb.LacI })_{\mathrm{r}}(2 \mathrm{~Pb} . t$ TA.B $) \mathrm{B}($ T.GFP.B $)$ fragments were gel-purified and then ligated to a gel-purified Ad5 genome backbone (Ad5sub360SR) digested on both ends with $X b a \mathrm{I}$. All Ad vectors are based on Ad5sub360SR, which contains deletions in E3 and all E4 ORFs with the exception of ORF6. The Ad/FasL-GFP DisTRES $_{\text {vector genome was }}$ constructed in the same way as described for Ad/GFP TRES, using a pRAd shuttle vector containing FasL-GFP subcloned in the place of GFP.

\section{Propagation of recombinant adenovirus vectors}

All vectors were propagated in HEK293 cells, using standard procedures [12,30,31]. Briefly, HEK293 cells were transfected with the complex Ad vector genome ligation mixture using Fugene 6 transfection reagent (Roche, Indianapolis, IN) following manufacturer's instructions. Transfected cells were maintained until adenovirusrelated cytopathic effects (CPE) were observed (typically 7-14 days post-transfection), at which point the cells were collected. Vector propagation and amplification was then achieved by standard techniques. Briefly, adenoviral lysates from twenty-four $150 \mathrm{~mm}$ plates were banded twice on $\mathrm{CsCl}$ gradients and desalted twice with a PD-10 size exclusion column (Amersham Scientific, Piscataway, NJ) into HEPES buffered saline (HBS; $21 \mathrm{mM}$ HEPES, 140 $\mathrm{mM} \mathrm{NaCl}, 5 \mathrm{mM} \mathrm{KCl}, 0.75 \mathrm{mM} \mathrm{Na}_{2} \mathrm{HPO}_{4} \cdot 2 \mathrm{H}_{2} \mathrm{O}$, and $0.1 \%(\mathrm{w} / \mathrm{v})$ dextrose; adjust $\mathrm{pH}$ with $\mathrm{NaOH}$ to 7.5 ; and filter sterilize) containing $5 \%$ glycerol, and stored at $-70^{\circ} \mathrm{C}$.

\section{Titering of recombinant adenovirus vector by infectious units}

All vectors were titrated on HEK293 cells infected in serial dilution on triplicate columns of 96-well plates for either GFP fluorescence or X-gal staining. GFP fluorescence was monitored with Axiovert-25 fluorescent microscope (Carl Zeiss, Germany) and FITC excitation/emission filter set (Chroma Technology Corp, Rockingham, VT) two days post-infection. Cells infected with Ad/C.LacZ were fixed two days post-infection with fixative solution ( $2 \%$ formaldehyde, $0.05 \%$ glutaraldehyde in $1 \times$ PBS) for 5 minutes at room temperature and then stained overnight at $37^{\circ} \mathrm{C}$ in $X$-gal solution (1 $\mathrm{mg} / \mathrm{ml}$ X-gal (5-Bromo-4-chloro-3indolyl- $\beta$-D-galactopyranoside), $5 \mathrm{mM}$ potassium ferricyanide, $5 \mathrm{mM}$ potassium ferrocyanide, $2 \mathrm{mM} \mathrm{MgCl}_{2}$ in $1 \times$ 
PBS). The resulting titers were scored as infectious units (IU) per ml.

\section{Titering of recombinant adenovirus vector by particle forming units}

All vectors were titrated on HEK293 cells infected in serial dilution on duplicate wells of 12-well plates. The day prior to infection, HEK293 cells were seeded with $2 \times 10^{5}$ cells/ml seeding density at $1 \mathrm{ml} /$ well. 4 to $16 \mathrm{hrs}$ postinfection, cells were overlaid with $1 \mathrm{ml} /$ well of $0.4 \%$ agar $(\mathrm{w} / \mathrm{v})$ in DMEM/2\% CCS and incubated at $37^{\circ} \mathrm{C}$ for $5-7$ days until indications of CPE were observed. Cells were fixed with $7 \%$ formaldehyde $\left(\mathrm{v} / \mathrm{v}\right.$ in $\left.\mathrm{dH}_{2} \mathrm{O}\right)$ solution at room temperature for $1 \mathrm{hr}$. Formaldehyde was aspirated from wells, and agar plugs were carefully removed. Fixed cells were stained for $10 \mathrm{~min}$ at room temperature with $0.2 \%$ crystal violet $\left(\mathrm{w} / \mathrm{v}\right.$ in $\left.\mathrm{dH}_{2} \mathrm{O}\right)$. Plaques were visualized using a standard light box. The resulting titers were scored as plaque forming units (pfu) per ml. In comparison to IU titers, pfu titers were approximately 2 logs lower. For example, the Ad/C.LacZ vector titer was $2.02 \times 10^{11}$ $\mathrm{IU} / \mathrm{ml}$ in infectious units and was $2.40 \times 10^{9} \mathrm{pfu} / \mathrm{ml}$ in particle-forming units.

\section{In vitro infections}

$1.25 \times 10^{4}$ cells/well were seeded in 96-well plates. Seeded cells were infected 3 hours post-seeding at varying multiplicities of infections (MOI), depending on the cell line. MOI calculations were based on cell numbers at the time of seeding and on Ad vector titers based on $\mathrm{IU} / \mathrm{ml}$ and $\mathrm{pfu} / \mathrm{ml}$, for GFP infections and FasL-GFP infections, respectively. In order to directly compare vector activity in prostate versus non-prostate cells, all cell types were infected in the presence of DHT, even though DHT would not likely be present under physiological conditions in non-prostate tissues.

\section{Quantification of GFP expression}

GFP fluorescence in cells was visualized 48 hours posttransduction using Axiovert-25 fluorescent microscope with FITC filter set. For quantitative analysis of GFP activity, cells were lysed with $0.5 \%$ Triton $\mathrm{x}-100$ in $1 \times$ PBS. Cell lysates were transferred to 96-well black microtiter plates (BMG Labtechnologies, Offenburg, Germany) and relative GFP fluorescence was measured using FLUOstar ${ }^{\mathrm{TM}}$ dual fluorescence/absorbance plate reader (BMG Labtechnologies) at excitation $485 \mathrm{~nm}$ and emission $520 \mathrm{~nm}$.

\section{Quantification of cell viability}

Two or three days post-infection, cells were fixed in 100\% methanol overnight at $-20^{\circ} \mathrm{C}$. Cell monolayers were stained with $0.2 \%$ crystal violet for $2 \mathrm{~min}$ at room temperature. Plates were washed twice with $\mathrm{dH}_{2} \mathrm{O}$ and then destained with $50 \mu \mathrm{l} /$ well of destain solution (30\% methanol, $10 \%$ acetic acid in $\mathrm{dH}_{2} \mathrm{O}$ ) for wells of 96 -well plate.
Plates were assayed for absorbance at $620 \mathrm{~nm}$. Percent viability was calculated by dividing the mean absorbance of each sample by the mean absorbance of $1 \times$ HBS mock infection and then multiplying by $100 \%$.

\section{Statistical analysis}

All assays were performed in duplicate and the results were expressed as the mean \pm standard error of the mean (SEM). Statistical analysis was determined using a twosample t-test.

\section{Authors' contributions}

JW constructed the DiSTRES adenovirus vectors, conducted all characterization experiments on the constructs, and also drafted the manuscript. SR participated in the overall design and cloning strategy for the DiSTRES constructs. HY constructed the control vectors and participated in the construction of the DiSTRES adenoviral constructs. JY conceived of the study and participated in the overall vector designs. All authors read and approved the final manuscript.

\section{Acknowledgements}

We would like to thank Robert J. Matusik, Department of Cell Biology, Vanderbilt University Medical Center, Nashville, TN, for providing the PARR2PB.Poll.TRZ-SK plasmid and Hermann Bujard, Center for Molecular Biology, University of Heidelberg, Heidelberg, Germany, for providing the PUHD I0-3, pUHD I5-I, and pUHS 6-I plasmids. We would like to thank the Brain Tumor Cell Core at UCSF for providing the U343MG and U25IMG brain tumor cell lines and Kerry L. Burnstein, Department of Molecular and Cellular Pharmacology, University of Miami School of Medicine, Miami, FL, for providing the PC3/AR cell line. We would like to acknowledge the MUSC Viral Vector Core Facility for help in the propagation and purification of the Ad/GFP ${ }_{\text {DisTRES }}, A d /$ FasL-GFP $_{\text {DisTRES }}$, and control vectors. This work was supported in part by a grant from the National Institutes of Health, ROI DK57997, and a startup fund provided to John Y. Dong by the Medical University of South Carolina.

\section{References}

I. Cancer Facts \& Figures 2007 [http://www.cancer.org]

2. Human Gene Transfer Protocols [http://www4.od.nih.gov/oba/ rac/PROTOCOL.pdf]

3. Garber K: China approves world's first oncolytic virus therapy for cancer treatment. I Natl Cancer Inst 2006, 98(5):298-300.

4. Guo J, Xin H: Chinese gene therapy. Splicing out the West? Science 2006, 3 | 4(5803): I 232-I 235.

5. Woraratanadharm J, Rubinchik S, Yu H, Fan F, Morrow SM, Dong JY: Highly specific transgene expression mediated by a complex adenovirus vector incorporating a prostate-specific amplification feedback loop. Gene Therapy 2004, I I ( I 8): | 399- | 407.

6. Gossen $M$, Bujard $\mathrm{H}$ : Tight control of gene expression in mammalian cells by tetracycline-responsive promoters. Proc Natl Acad Sci U S A 1992, 89( I 2):5547-555I.

7. Zhang J, Thomas TZ, Kasper S, Matusik RJ: A small composite probasin promoter confers high levels of prostate-specific gene expression through regulation by androgens and glucocorticoids in vitro and in vivo. Endocrinology 2000, I 4 I ( I 2):4698-47I0.

8. Freundlieb S, Schirra-Muller C, Bujard H: A tetracycline controlled activation/repression system with increased potential for gene transfer into mammalian cells. J Gene Med 1999, I(I):4-I 2.

9. Rubinchik S, Wang D, Yu H, Fan F, Luo M, Norris JS, Dong JY: A complex adenovirus vector that delivers FASL-GFP with 
combined prostate-specific and tetracycline-regulated expression. Mol Ther 200I, 4(5):4I6-426.

10. Rubinchik S, Lowe S, Jia Z, Norris J, Dong J: Creation of a new transgene cloning site near the right ITR of Ad5 results in reduced enhancer interference with tissue-specific and regulatable promoters. Gene Ther 200I, 8(3):247-253.

II. Dai JL, Maiorino CA, Gkonos PJ, Burnstein KL: Androgenic up-regulation of androgen receptor CDNA expression in androgenindependent prostate cancer cells. Steroids 1996 6I(9):53I-539.

12. Rubinchik S, Ding R, Qiu AJ, Zhang F, Dong J: Adenoviral vector which delivers FasL-GFP fusion protein regulated by the tetinducible expression system. Gene Ther 2000, 7(10):875-885.

13. Block A, Milasinovic D, Mueller J, Schaefer P, Schaefer H, Greten H: Amplified Mucl-specific gene expression in colon cancer cells utilizing a binary system in adenoviral vectors. Anticancer Res 2002, 22(6A):3285-3292.

14. Fang B, Ji L, Bouvet M, Roth JA: Evaluation of GAL4/TATA in vivo. Induction of transgene expression by adenovirally mediated gene codelivery. J Biol Chem 1998, 273(9):4972-4975.

15. Hattori $Y$, Maitani $Y$ : Two-step transcriptional amplificationlipid-based nanoparticles using PSMA or midkine promoter for suicide gene therapy in prostate cancer. Cancer Sci 2006 , 97(8):787-798.

16. Kagawa S, Pearson SA, Ji L, Xu K, McDonnell TJ, Swisher SG, Roth JA, Fang B: A binary adenoviral vector system for expressing high levels of the proapoptotic gene bax. Gene Ther 2000, 7(1):75-79.

17. Zhang L, Adams JY, Billick E, llagan R, lyer M, Le K, Smallwood A Gambhir SS, Carey M, Wu L: Molecular engineering of a twostep transcription amplification (TSTA) system for transgene delivery in prostate cancer. Mol Ther 2002, 5(3):223-232.

18. Volk AL, Rivera AA, Kanerva A, Bauerschmitz G, Dmitriev I, Nettelbeck DM, Curiel DT: Enhanced Adenovirus Infection of Melanoma Cells by Fiber-Modification: Incorporation of RGD Peptide or Ad5/3 Chimerism. Cancer Biol Ther 2003, 2(5):5I|-5I5.

19. Buskens CJ, Marsman WA, Wesseling JG, Offerhaus GJ, Yamamoto M, Curiel DT, Bosma PJ, van Lanschot J]: A genetically retargeted adenoviral vector enhances viral transduction in esophageal carcinoma cell lines and primary cultured esophageal resection specimens. Ann Surg 2003, 238(6):8I5-24; discussion 825-6.

20. Belousova N, Krendelchtchikova V, Curiel DT, Krasnykh V: Modulation of adenovirus vector tropism via incorporation of polypeptide ligands into the fiber protein. J Virol 2002, 76(17):862I-863I.

21. Wesseling JG, Bosma PJ, Krasnykh V, Kashentseva EA, Blackwell JL, Reynolds PN, Li H, Parameshwar M, Vickers SM, Jaffee EM, Huibregtse K, Curiel DT, Dmitriev I: Improved gene transfer efficiency to primary and established human pancreatic carcinoma target cells via epidermal growth factor receptor and integrin-targeted adenoviral vectors. Gene Ther 200I, 8(I3):969-976.

22. Heideman DA, Snijders PJ, Craanen ME, Bloemena E, Meijer CJ, Meuwissen SG, van Beusechem VW, Pinedo HM, Curiel DT, Haisma HJ, Gerritsen WR: Selective gene delivery toward gastric and esophageal adenocarcinoma cells via EpCAM-targeted adenoviral vectors. Cancer Gene Ther 200I, 8(5):342-35I.

23. Vigne E, Dedieu JF, Brie A, Gillardeaux A, Briot D, Benihoud K, LattaMahieu M, Saulnier P, Perricaudet M, Yeh P: Genetic manipulations of adenovirus type 5 fiber resulting in liver tropism attenuation. Gene Ther 2003, 10(2):153-162.

24. Nakamura T, Sato K, Hamada H: Reduction of natural adenovirus tropism to the liver by both ablation of fiber-coxsackievirus and adenovirus receptor interaction and use of replaceable short fiber. J Virol 2003, 77(4):25I2-252I.

25. Jongmans W, van den Oudenalder K, Tiemessen DM, Molkenboer J Willemsen R, Mulders PF, Oosterwijk E: Targeting of adenovirus to human renal cell carcinoma cells. Urology 2003, 62(3):559-565.

26. Nettelbeck DM, Rivera AA, Kupsch J, Dieckmann D, Douglas JT, Kontermann RE, Alemany R, Curiel DT: Retargeting of adenoviral infection to melanoma: combining genetic ablation of native tropism with a recombinant bispecific single-chain diabody (scDb) adapter that binds to fiber knob and HMWMAA. Int J Cancer 2004, I 08(I): | $36-145$.
27. van Beusechem VW, Mastenbroek DC, van den Doel PB, Lamfers ML, Grill J, Wurdinger T, Haisma HJ, Pinedo HM, Gerritsen WR: Conditionally replicative adenovirus expressing a targeting adapter molecule exhibits enhanced oncolytic potency on CAR-deficient tumors. Gene Ther 2003, 10(23): |982-199|.

28. Henning $P$, Magnusson MK, Gunneriusson E, Hong SS, Boulanger $P$, Nygren PA, Lindholm L: Genetic modification of adenovirus 5 tropism by a novel class of ligands based on a three-helix bundle scaffold derived from staphylococcal protein A. Hum Gene Ther 2002, I 3(I 2): | 427- | 439.

29. Kashentseva EA, Seki T, Curiel DT, Dmitriev IP: Adenovirus targeting to c-erbB-2 oncoprotein by single-chain antibody fused to trimeric form of adenovirus receptor ectodomain. Cancer Res 2002, 62(2):609-616.

30. Rubinchik S, Norris JS, Dong JY: Construction, purification and characterization of adenovirus vectors expressing apoptosisinducing transgenes. Methods Enzymol 2002, 346:529-547.

31. Rubinchik S, Woraratanadharm J, Schepp J, Dong JY: Improving the transcriptional regulation of genes delivered by adenovirus vectors. Methods in Molecular Medicine 2003, 76:167-199.

Publish with Biomed Central and every scientist can read your work free of charge

"BioMed Central will be the most significant development for disseminating the results of biomedical research in our lifetime. "

Sir Paul Nurse, Cancer Research UK

Your research papers will be:

- available free of charge to the entire biomedical community

- peer reviewed and published immediately upon acceptance

- cited in PubMed and archived on PubMed Central

- yours - you keep the copyright 